\title{
ANÁLISIS DE LOS CURSOS DE FILOSOFÍA AMBIENTAL DE CAMPO EN EL PARQUE ETNOBOTÁNICO OMORA, RESERVA DE LA BIOSFERA CABO DE HORNOS, CHILE
}

\author{
JAVIERA MALEBRÁN ${ }^{\mathrm{a}, \mathrm{b}}$, RICARDO ROZZl $\mathrm{l}^{\mathrm{b}, \mathrm{d}}$
}

\section{RESUMEN}

Uno de los causantes del cambio socio-ambiental global es la creciente tasa de urbanización mundial, con más de la mitad de la población habitando en ambientes urbanos. La concentración de la población en las urbes genera una desconexión entre la sociedad y los ambientes naturales y un desconocimiento de la diversidad biocultural asociada a ellos. Esta desconexión fomenta procesos de homogeneización biocultural alrededor del mundo. En el Parque Omora, el sitio más austral de la Red Chilena de Estudios Socio-Ecológicos a Largo Plazo, se ha desarrollado una aproximación metodológica que a través de prácticas de investigación, educación y conservación intenta remediar esta desconexión y falta de empatía: la Filosofía Ambiental de Campo (FILAC). Esta metodología procura fomentar un sentimiento de preocupación, cuidado y protección de la diversidad biocultural y revertir la tendencia global hacia una homogeneización biocultural. Este trabajo se centra en el curso internacional FILAC que se realiza anualmente en el Parque Omora. Se examinan los cursos ofrecidos el 2015, 2016, 2017 y 2018. Los participantes, provenientes de distintas regiones del mundo y distintas disciplinas, se sumergen en un ambiente académico, natural, social e institucional donde los participantes viven experiencias interculturales e interdisciplinarios que promueven y orientan una transformación en los modos de observar, comprender y valorar la diversidad biocultural, aprendiendo y aprehendiendo distintos y nuevos puntos de vista. Los participantes recuperaron prácticas esenciales para los naturalistas y lograron integrar las dimensiones biofísicas y culturales implicadas en el trabajo de investigación, educación y conservación biocultural. Esta integración considera tanto puntos de vista de las ciencias, la filosofía y las artes, como los propios ámbitos de estudio y áreas de desarrollo profesional y personal de cada participante. Se discute el potencial de aplicación de cursos de campo similares en otros sitios de estudios socio-ecológicos a largo plazo y áreas de conservación en el mundo, y cómo estos sitios podrían aportar a una reconexión de los estudiantes y otros grupos sociales con la diversidad biocultural de sus regiones.

PALABRAS CLAVE: Educación ambiental, historia natural, ética ambiental, interdisciplinario, intercultural.

a Estudiante de Biología con mención en Medio Ambiente, Facultad de Ciencias, Universidad de Chile, Las Palmeras 3425, Nuñoa, Santiago, Chile. $\$ javiera.malebran@gmail.com

b Instituto de Ecología y Biodiversidad de Chile (IEB).

Parque Etnobotánico Omora, IEB y Universidad de Magallanes. Puerto Williams, Provincia Antártica Chilena, Chile.

d Sub-Antarctic Biocultural Conservation Program, Department of Philosophy and Religion \& Department of Biological Sciences, University of North Texas, 1704 West Mulberry, Denton, TX 76201, USA. 


\title{
ANALYSIS OF THE ENVIRONMENTAL FIELD PHILOSOPHY COURSES AT THE OMORA ETNOBOTÁNICO PARK, BIOSPHERE RESERVE CABO DE HORNOS, CHILE
}

\begin{abstract}
One of the drivers of the global socio-environmental change is the growing rate of urbanization, with more than half of the world's population living in urban environments. This trend fosters biocultural homogenization throughout the world and results in a disconnection between society and natural environments and, therefore, a lack of knowledge about the biocultural diversity associated to them. The concentration of the population in the cities generates a disconnection between society and natural environments, and a lack of knowledge of the biocultural diversity associated with them. This disconnection fosters processes of biocultural homogenization around the world. At the Omora Ethnobotanical Park, the southernmost site of the Chilean network of Long-Term Socio-Ecological Research (LTSER) sites, a methodological approach has been developed that through research, education and conservation practices aims to remedy this disconnection and lack of empathy: Field Environmental Philosophy (FEP). This methodology seeks to foster a sense of concern, care and protection of biocultural diversity, and reverse the global trend towards a biocultural homogenization. This article focuses on the international FEP course that takes place annually at Omora Park, examining the courses that were offered in 2015, 2016, 2017 and 2018. Participants from different regions of the world and different disciplines immerse themselves in an academic, natural, social and institutional environment. They live intercultural and interdisciplinary experiences that guide a transformation in the ways of observing, understanding and valuing biocultural diversity, learning and apprehending different and new points of view. Participants recover essential practices for naturalists and managed to integrate the biophysical and cultural dimensions involved in biocultural research, education, and conservation. This integration considers the points of view of science, philosophy and the arts, as well as the areas of professional and personal development of each participant. The potential for application of similar field courses in other sites of long-term socio-ecological studies and conservation areas in the world is discussed, and how these sites could contribute to a reconnection of students and other social groups with the biocultural diversity of their regions.
\end{abstract}

KEY WORDS: environmental education, natural history, environmental ethics, interdisciplinary, intercultural.

\section{INTRODUCCIÓN}

La forma en que los seres humanos percibimos y nos relacionamos con el mundo depende de nuestros entornos sociales y naturales. Ya sea que vivamos en ciudades o en el campo, los elementos de la naturaleza inciden en la materialidad, los conceptos $y$ el imaginario de las personas: bebemos agua, respiramos aire, comemos frutas, etc. Sin embargo, existe una marcada diferencia entre quienes habitan en ciudades y quienes habitan en entornos más naturales (Leopold, 2004). Al pensar en agua, los habitantes

1 Sobre el contraste entre los imaginarios de habitantes urbanos y rurales, véase la tesis sobre "Extinción de la urbanos piensan en una cañería o un grifo, mientras que los habitantes rurales piensan en un lago o en un río. Al respirar, unos se ven forzados a pensar en niveles de contaminación atmosférica, mientras que los otros no piensan porque simplemente respiran aire puro. Al tener que ir a buscar frutas, unos piensan en una sección del supermercado y los otros piensan en árboles y arbustos. ${ }^{1}$

Estas diferencias se han exacerbado como resultado de un proceso de urbanización acelerado: desde el año 2007 más de la mitad de la población mundial habita en ciudades (UN, 2010). Esta

experiencia” de Alexandria Poole, (2015). 
concentración de la población en ambientes urbanos ha conllevado una progresiva desconexión con los entornos naturales, incluso en la ciudad más austral del planeta, Puerto Williams (Rozzi et al. 2008). Tal como plantea Humberto Maturana en su prólogo al libro La Enseñanza de la Ecología en el Entorno Cotidiano:

Pertenecemos a una historia cultural que nos separa cada vez más del mundo natural. En la ciudad crecemos sin conocer los nombres de las plantas autóctonas o de los animales silvestres que aún pueden verse en nuestro entorno, a menos que los estudiemos especialmente. Ya no aprendemos como algo natural lo natural de nuestra pertenencia a la biósfera e interdependencia vital con todos los otros seres vivos que la constituyen y con los componentes no vivos de la corteza terrestre. Ya casi no nos reconocemos en nuestro entorno, pues éste, en su extrema artificialidad, nos niega y oculta lo que es nuestro fundamento animal y vegetal (Maturana, 1997, pp. 3-6).

Este artículo tiene como objetivo presentar una aproximación metodológica aporta un enfoque educativo que contribuye a resolver la desconexión entre la sociedad urbana y la diversidad biológica y cultural y sus interrelaciones, esto es: la diversidad biocultural. Para reconectar la sociedad con la diversidad biocultural también existen múltiples plataformas institucionales y metodológicas vinculadas a sectores académicos (universidades y centros de investigación), organizaciones no gubernamentales (ONGs) y otras formas organizadas de la sociedad civil que se enfocan en problemáticas socio-ambientales. Una de estas plataformas institucionales corresponde a la red Chilena de sitios de estudios socio-ecológicos a largo plazo (LTSER-Chile) (Rozzi et al. 2012a), y a la Red Internacional de Sitios de estudios ecológicos a largo plazo (ILTER, por su sigla en inglés, International Long-Term Ecological Research

2 El naturalista británico Charles Darwin pasó una parte significativa de su viaje a bordo del HMS Beagle en el extremo austral de Sudamérica. En Cabo de Hornos comenzó a concebir su teoría de la evolución humana, teoría que hoy tiene implicancias centrales para la ética ambiental contemporánea (Rozzi, 1999, 2018). Con actividades de observación, dibujo y análisis del entorno y de textos científicos y filosóficos, este curso intenta recuperar prácticas network), que reúne más de 500 sitios alrededor del mundo (Maass et al. 2016). La red ILTER ha hecho un esfuerzo por integrar las dimensiones ecológicas y sociales del cambio global, sin embargo, aún persiste una carencia fundamental en las dimensiones sociales abordadas (Maass \& Equihua, 2014). Hasta hoy, los estudios socio-ecológicos han avanzado en la inclusión de las ciencias económicas y otras áreas, pero han omitido la incorporación de la filosofía y la ética, de sus marcos conceptuales y prácticos. La incorporación de variables económicas en los estudios socio-ecológicos es necesaria, pero no suficiente. Para aportar a la construcción de un enfoque socioambiental más amplio, el equipo de investigadores del Parque Omora, el sitio ILTER más austral de América y sitio co-fundador de LTSER-Chile, ha desarrollado una aproximación metodológica denominada Filosofía Ambiental de Campo (FILAC) (Rozzi et al. 2014).

La metodología de la FILAC integra las humanidades, las artes y la filosofía en programas de estudios socio-ecológicos a largo plazo e iniciativas de conservación biocultural. LA FILAC se organiza en un ciclo de cuatro pasos interconectados. Esta aproximación metodológica se fundamenta en el marco teórico de las "3Hs" de la ética biocultural que valora los vínculos vitales entre el bienestar e identidad de comunidades de co-habitantes (humanos y no-humanos), sus hábitos de vida y los hábitats específicos donde éstos tienen lugar (Rozzi, 2013). Estos marcos metodológico y teórico orientan una investigación transdisciplinaria y su integración en programas de educación y conservación biocultural (Rozzi et al. 2012a).

Una de las formas de poner en práctica la metodología de la FILAC es la realización de cursos que van desde el nivel preescolar hasta el postgrado, como también la realización de talleres de formación técnica (Rozzi et al. 2010). Un curso emblemático ha sido el curso internacional Filosofía Ambiental de Campo (Field Environmental Philosophy), llamado Tracing

de naturalistas como Charles Darwin, Aldo Leopold y otros autores importantes no solo para la ciencia, sino también para la filosofía. Por esta razón, en UNT el curso recibe el nombre de Tracing Darwin's Path. Cabe señalar que en la UMAG el curso se llama Conservación Biocultural de Campo debido a que forma parte de los programas de posgrado en ciencias subantárticas y antárticas, que tienen una mención en conservación biocultural. 
Darwin's Path (TDP) $)^{2}$ en su versión inglesa, que es ofrecido por el Programa de Conservación Biocultural Subantártica (Programa CBS). El Programa CBS es coordinado por la Universidad de Magallanes (UMAG), el Instituto de Ecología y Biodiversidad (IEB) y la Fundación Omora en Chile, y por la University of North Texas (UNT) y el Center for Environmental Philosophy en EE.UU. Estudiantes de pre y postgrado, junto a un grupo de académicos de distintos países y áreas del conocimiento, participan en un curso intensivo de tres semanas que se realiza cada año en el Parque Omora ubicado a $3 \mathrm{~km}$ de Puerto Williams $\left(55^{\circ} \mathrm{S}\right)$. Esta ciudad es la capital de la Provincia Antártica Chilena, y el Parque Omora funciona como centro de investigación y educación en la Reserva de la Biosfera Cabo de Hornos (Fig. 1). Este curso se realizó por primera vez en el año 2000 y en el 2005 se incorporó a las mallas curriculares de UMAG y UNT.

En este trabajo presentamos y analizamos las actividades del curso internacional TDP entre los años 2015 y 2018. A través de ejemplos ilustrativos de actividades de la FILAC, exponemos un enfoque metodológico que puede ser adaptado en otros contextos socioambientales. Exponemos la diversidad de los participantes, sus procedencias y disciplinas, con el fin de examinar el valor de esta diversidad para el desarrollo de la FILAC. Analizamos el grado de interculturalidad e interdisciplinariedad del curso, y la forma en que la FILAC orienta una transformación en los participantes en su capacidad de observar, comprender y valorar la diversidad biocultural. Discutimos las potencialidades de aplicación de la FILAC y sus cursos de campo en otros sitios ILTER o áreas de conservación, investigación y/o educación, con el fin de contribuir a la reconexión entre distintos grupos sociales y la diversidad biocultural de sus regiones.

\section{METODOLOGÍA}

\section{Sitio de estudio}

El curso internacional Filosofía Ambiental de Campo se desarrolla en la Región de
Magallanes y Antártica Chilena, en el extremo sur del Continente Americano (Fig. 1). Las actividades se llevan a cabo en las ciudades Punta Arenas y sus alrededores, además de Puerto Williams y el Parque Etnobotánico Omora, y otros sectores de la Reserva de la Biósfera Cabo de Hornos $\left(55^{\circ} \mathrm{S}\right)$.

Puerto Williams es una ciudad pequeña y remota, con aproximadamente 2500 habitantes. La temperatura media anual es de $5,6^{\circ} \mathrm{C}$ y las precipitaciones alcanzan $500 \mathrm{~mm} / \mathrm{año,} \mathrm{con}$ ocurrencia de nevadas incluso en verano (Rozzi \& Jiménez, 2014). El acceso a algunos servicios en esta ciudad es limitado, por ejemplo internet, vegetales frescos, especialidades médicas y otras. Estas condiciones generan experiencias nuevas para los estudiantes que arriban a una zona extrema. Por otro lado, esta zona alberga algunos de los ecosistemas menos alterados en el siglo XXI, y posee un patrimonio arqueológico, histórico y ecológico de extraordinario valor, incluyendo paisajes con un alto valor estético.

\section{Curso internacional}

Filosofía Ambiental de Campo (TDP)

El curso internacional Filosofía Ambiental de Campo (TDP) es dictado principalmente en inglés. Expone a estudiantes de universidades chilenas y extranjeras a experiencias interculturales $e$ interdisciplinarias de investigación, conservación y educación biocultural en una de las últimas áreas prístinas del planeta. A través de estas experiencias de campo se orienta a los participantes a explorar diversas formas de percibir, indagar, definir, valorar y conservar la diversidad biocultural. Se procura que la metodología de la FILAC entregue conceptos y prácticas que sean aplicables tanto durante el curso en la $\mathrm{RBCH}$, como también posteriormente en los lugares de origen de los participantes, que incluyen ambientes urbanos. Las formas de indagar la diversidad biocultural incluyen perspectivas de las artes y la filosofía, las ciencias modernas y del conocimiento ecológico tradicional albergado por pueblos originarios, tales como el pueblo yagán, originario de la región de los canales australes.

El TDP se organiza en tres secciones que 


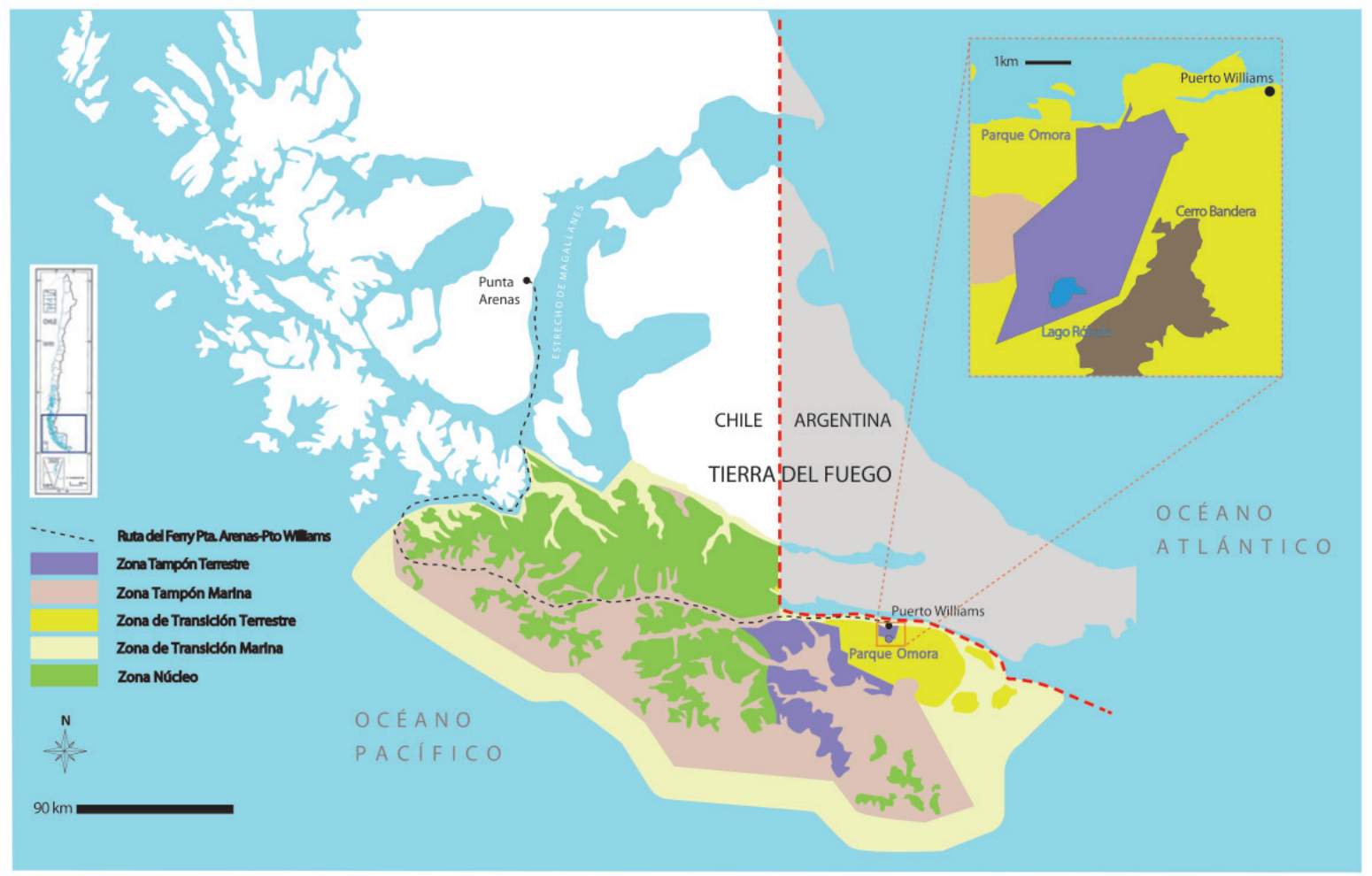

Fig. 1. Mapa de zonificación la Reserva de la Biosfera Cabo de Hornos (RBCH) y ubicación del Parque Omora en el extremo austral de América. La línea entrecortada negra, entre Punta Arenas y Puerto Williams, indica la ruta de navegación que realizan los estudiantes al inicio del curso internacional Filosofía Ambiental de Campo.

aplican la FILAC, integrando investigación en ecosistemas terrestres, acuáticos y marinos, en conjunto con investigación en dimensiones filosóficas y éticas de la conservación biocultural. La primera sección introduce a los alumnos al contexto biofísico y cultural de la Región de Magallanes por medio de visitas guiadas, observación detallada y pausada a través del dibujo, experiencias interculturales, visitas a distintas instituciones y encuentros con representantes de diversos grupos socioculturales. La segunda sección ahonda en los estudios socio-ecológicos a largo plazo, en particular en el sitio de LTSER-Chile Parque Omora, complementado por el análisis y discusión de textos de filosofía y ética ambiental. En la tercera sección del curso, los estudiantes deben comunicar a sus compañeros y profesores lo aprendido durante las dos primeras secciones. Para esto se practica el pensamiento analógico en un proceso de creación de metáforas y narrativas simples a través del cual los estudiantes comprenden el papel determinante que juegan el lenguaje y la cultura en los relatos científicos, históricos, filosóficos y otros. En sus composiciones los participantes son alentados a interrelacionar hechos y valores. Se procura que practiquen la elaboración de relatos que puedan explicar conceptos 0 procesos ecológicos complejos y valores ambientales y culturales de forma simple, que sean comprensibles y puedan inspirar sentimientos de empatía en los interlocutores. De esta manera, se orientan procesos de reconexión con la diversidad biocultural.

La FILAC se organiza metodológicamente en un ciclo de cuatro pasos interconectados (Fig. 2) que integran las ciencias, las artes, la filosofía y otras disciplinas.

\section{Paso 1:}

Indagación interdisciplinaria

El curso TDP tiene un enfoque experiencial 


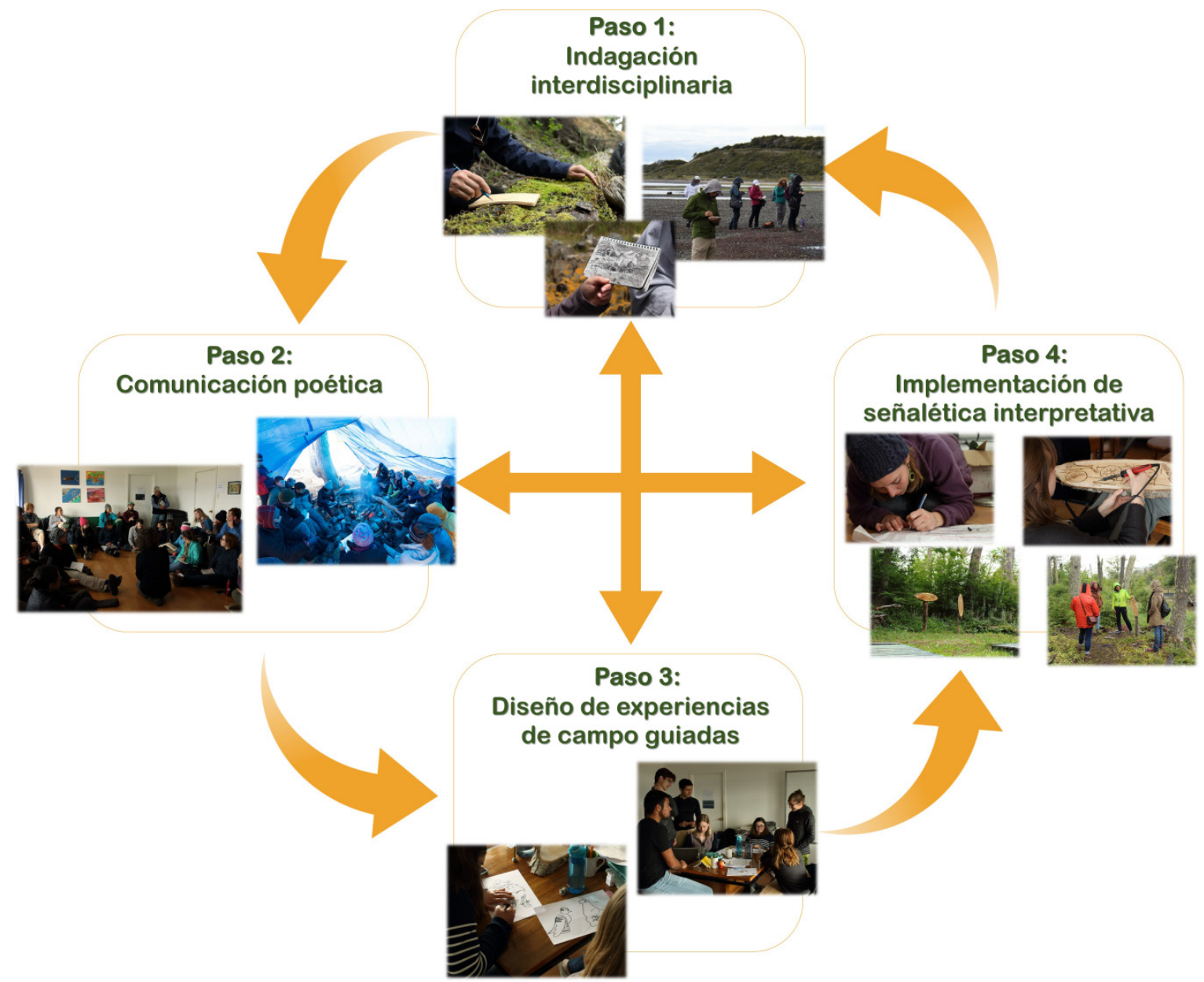

Fig. 2. Ciclo de cuatro pasos interconectados de la aproximación metodológica Filosofía Ambiental de Campo (FILAC), desarrollada en el Parque Omora, que integra ciencias, artes, filosofía y ética (entre otras disciplinas) tanto en la teoría como en la práctica. Fotos: J. Malebrán.

que reconecta a los participantes con los hábitats $y$ sus diversos co-habitantes. En terreno, los participantes del TDP viven encuentros caraa-cara con estos co-habitantes en los distintos ecosistemas subantárticos (Fig. 3). En estos encuentros, los estudiantes aprenden a observar los hábitats y sus co-habitantes desde puntos de vista ecológicos, filosóficos y artísticos. Las sesiones de trabajo del Paso 1 requieren que los participantes adopten un ritmo más pausado para desenvolverse en sus entornos y así fomentar una re-conexión con el medio natural. Aprenden a observar, indagar y también reflexionar sobre los modos de co-habitar con la diversidad biocultural.

Las primeras actividades del curso consisten en presentar el contexto biofísico.
Los estudiantes inician su experiencia viajando en transbordador desde Punta Arenas por el Estrecho de Magallanes, el canal Ballenero y el canal Beagle hasta Puerto Williams (Fig. 1). La navegación dura aproximadamente 32 horas a lo largo de canales y fiordos, con impresionantes vistas de islas, saltos de agua, ventisqueros y avistando una diversidad de fauna marina. En Puerto Williams, una de las primeras actividades es el ascenso hasta la cumbre del cerro Bandera con estaciones a distintas altitudes, permite observar la complejidad y dinamismo del ecosistema boscoso. Luego de estas actividades iniciales se realiza un campamento de cuatro días a orillas del lago Róbalo en la montaña. El ascenso al lago requiere una caminata de 4 kilómetros. 
Estas actividades brindan a los alumnos la oportunidad de conocer de manera experiencial el entorno biofísico donde están inmersos (Fig. 3A,G,I). En terreno trabajan con artistas, filósofos, científicos y miembros de la comunidad yagán. Además del intenso trabajo en terreno, se realizan sesiones en sala y en laboratorio que introducen a los estudiantes al trabajo que se realiza en el parque. En el laboratorio aprenden a identificar diversos grupos de organismos, tales
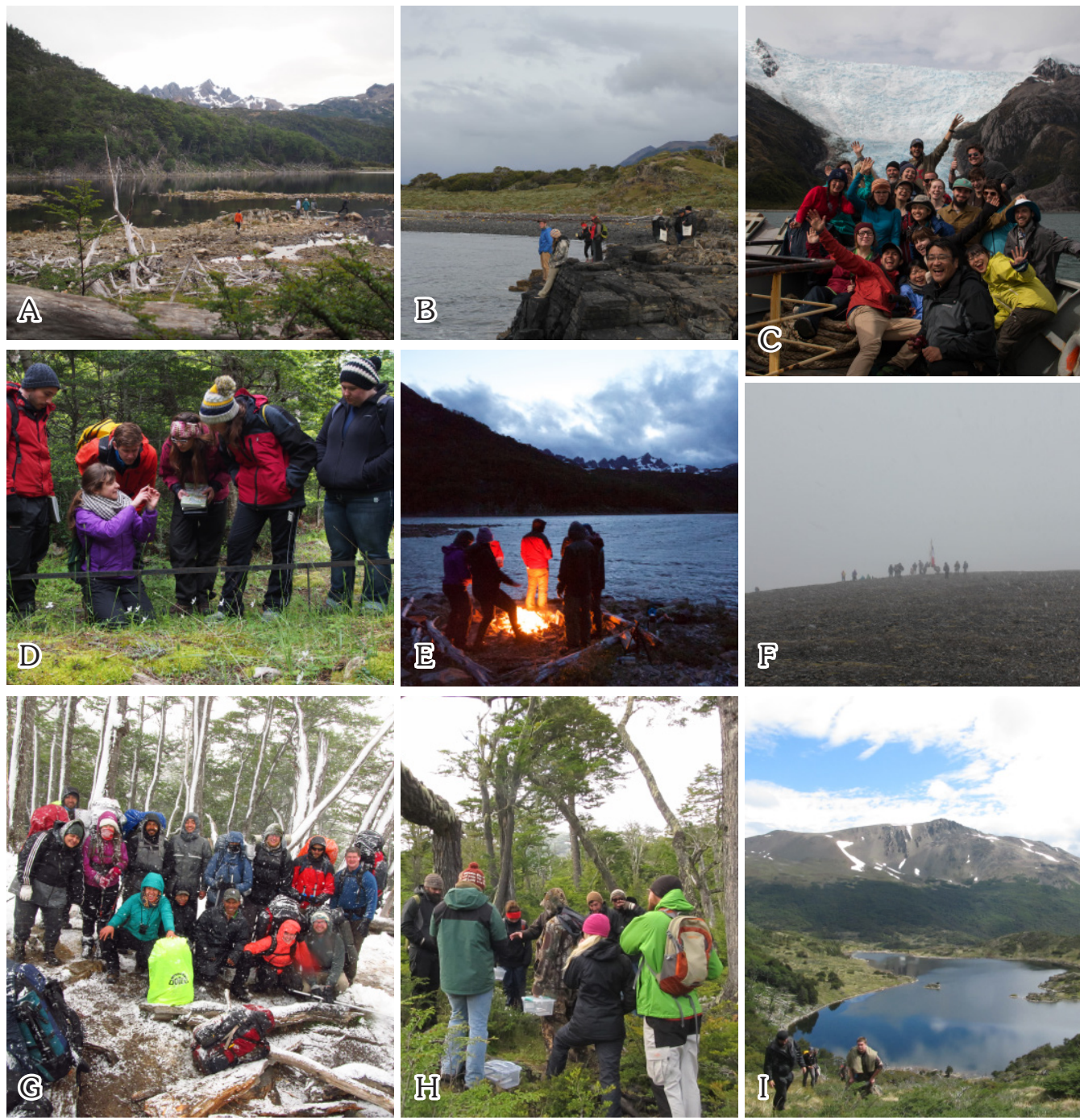

Fig. 3. Ilustraciones de algunas actividades de terreno donde los participantes del curso TDP tienen encuentros directos con la naturaleza y sus co-habitantes en distintos tipos de hábitats subantárticos. A) En hábitats ribereños a orilla del lago Róbalo. B) En hábitats costero-marinos a orillas del Canal Beagle en una actividad intercultural con poetas, arqueólogos y briólogos (estudiosos de los musgos) del congreso de la International Association of Bryology (IAB), Puerto Williams 2015. C) En hábitats de fiordos y canales frente al glaciar Italia en el Canal Beagle, durante la navegación entre Punta Arenas y Puerto Williams. D) En hábitats de bosque siempreverde en el Parque Omora aprendiendo a observar musgos

en el sotobosque. E) En hábitats ribereños a orillas del lago Róbalo. F) En hábitats altoandinos con científicos del congreso IAB en el cerro Bandera, aledaño a Puerto Williams. G) En hábitats de bosque mixto bajo nevazones estivales en la isla Navarino. H) En hábitats riparianos en el río Róbalo en el Parque Omora estudiando invertebrados dulceacuícolas. I) En hábitats ecotonales en el límite arbóreo subiendo por el valle del río Róbalo. Fotos: A, D, Megan Fitch; B, F, Jeff Hammond; C, Bruno Becker; E, Matthew Packer; G, H, I, Javiera Malebrán. 
como distintas especies de musgos, hepáticas, líquenes o macroinvertebrados acuáticos, con lupas y microscopios.

La dimensión ecológica se aborda a través del monitoreo de biodiversidad en cuatro áreas en que los estudiantes participan activamente:

- Ornitología: captura y anillamiento de aves. Monitoreo a largo plazo de aves de bosque en redes de neblina que se realiza en el Parque Omora desde el año 2000 (Rozzi \& Jiménez, 2014).

- Ecología dulceacuícola: muestreo de la calidad de las aguas y la historia de vida de los macroinvertebrados que habitan la cuenca del río Róbalo. Monitoreo a largo plazo iniciado en el año 2008 (Contador et al. 2015).

- Briología: reconocimiento de la gran diversidad de briófitas (musgos, hepáticas y antocerotes) y líquenes que existe en la zona, a través del ecoturismo con lupa. En terreno y en laboratorio los alumnos estudian la morfología de estos grupos y su importancia ecológica (Goffinet et al. 2012).

- Ecología de invasiones: introducción a las problemáticas socio-ambientales que pueden provocar plantas y animales exóticos y los impactos que han tenido especies invasoras en la isla Navarino específicamente, y en los ecosistemas en general (Schüttler et al. 2009).

La dimensión artística incluye la observación detallada de los entornos. El análisis de las formas y hábitos de vida de los organismos se practica a través de la contemplación y del dibujo utilizando diversas técnicas y materiales. Según Villagrán et al. (2014) estas prácticas forman parte de la tradición del naturalista que se ha perdido en la educación formal actual. La FILAC enfatiza que el dibujo es un proceso lento que requiere la observación en detalle, y orienta una conexión con el "sujeto" dibujado (Rozzi et al. 2008). De esta manera, se recuperan estas antiguas prácticas naturalistas de observar y vincularse con la naturaleza. Se dibujan seres, objetos o paisajes que llamen la atención del estudiante quien descubre rasgos o características que de otra manera podrían pasar por alto (Fig. 4).

La dimensión filosófica y ética se aborda desde dos tipos de actividades. Por un lado, se fomenta el pensamiento crítico por medio de la lectura y el análisis de textos filosóficos. Para ello se utilizan múltiples "lentes conceptuales". Por otro lado, la dimensión ética del co-habitar en la naturaleza se observa y analiza a partir de experiencias interdisciplinarias e interculturales. Estas experiencias integran dimensiones científica y artística. Estas dos actividades permiten comprender realidades biofísicas y valóricas que reconectan la cultura con la naturaleza. Una experiencia intercultural esencial es la práctica de saberes tradicionales con artesanos de la comunidad yagán quienes, por ejemplo, enseñan de manera integral el tejido de cestos de juntos. En efecto, Julia González, artesana yagán residente de la isla Navarino, es maestra formal en este curso (Fig. 5).

Otro ejemplo de experiencia intercultural importante fue el encuentro de los alumnos del curso TDP-2015 con el poeta Lorenzo Aillapan, hombrepájaro mapuche o Üñumche (Fig. 6). Don Lorenzo mostró elementos de la cultura mapuche a los estudiantes a través de imitaciones onomatopéyicas de los cantos de pájaros que habitan tanto en su región como en la ecorregión subantártica de Magallanes. Sus poemas recitados en español fueron traducidos al inglés por estudiantes chilenas del curso. Posteriormente, en una visita a un sitio arqueológico de la isla Navarino, los participantes, liderados por don Lorenzo, dieron gracias a la Madre Tierra, Pachamama, por recibirnos en ese lugar y brindarnos sus frutos y su belleza.

\section{Paso 2:}

\section{Comunicación poética y metafórica}

Los participantes deben componer metáforas y narrativas simples para comunicar sus aprendizajes y observaciones. Las metáforas son figuras utilizadas ampliamente por la cultura. Representan imágenes mentales que sintetizan conceptos complejos de manera que puedan ser comprendidos, y también comunicados, a través de un pensamiento analógico. Facilitan la vinculación de diferentes disciplinas (Oelschlaeger \& Rozzi, 1998) y ayudan a entender nociones interdisciplinarias como las resultantes de las investigaciones desarrolladas en el Paso 1 de la FILAC. 


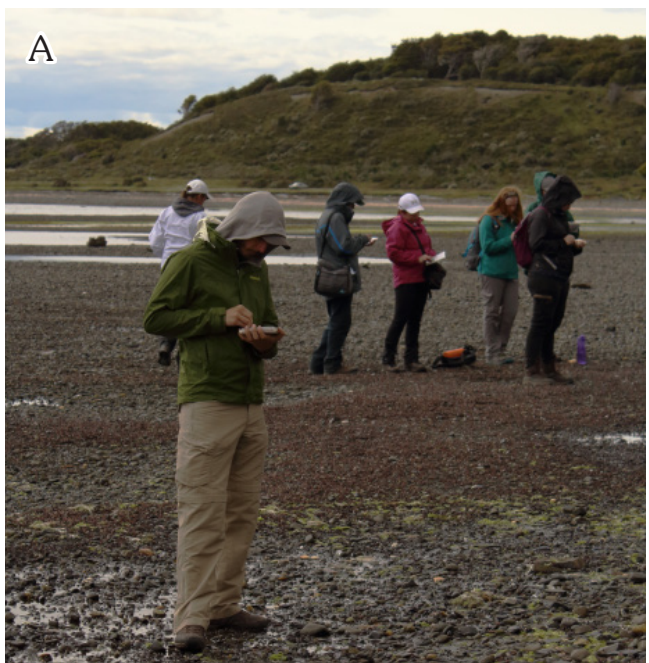

B
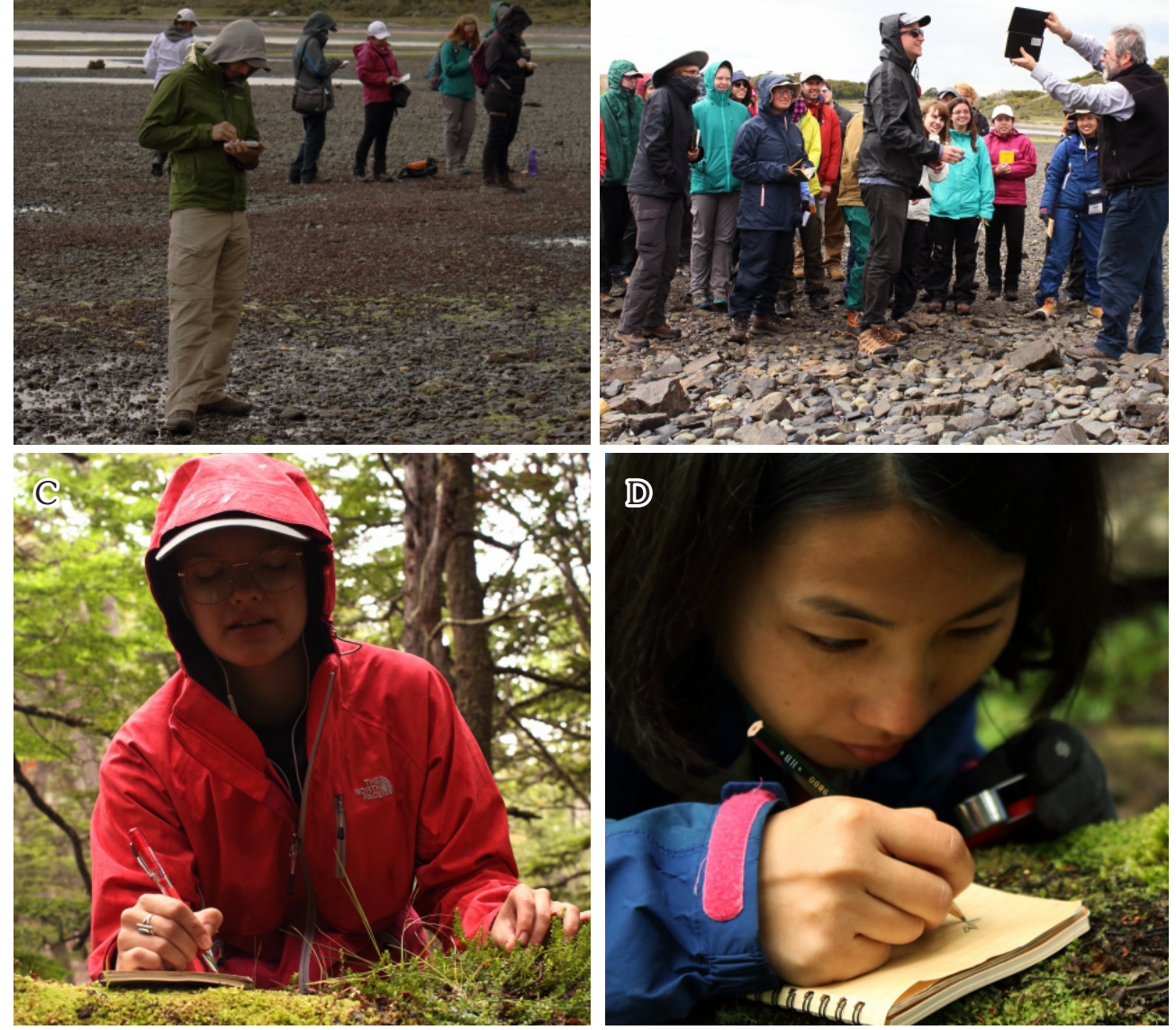

Fig. 4. Ilustraciones de algunas experiencias de dibujo en terreno con estudiantes del curso TDP-2017.

A) Dibujando el paisaje que observan en la playa de la bahía Robalo, isla Navarino. B) Observando y comentando los dibujos del grupo. C) Dibujando con los ojos cerrados para conectarse a través del tacto con el sujeto retratado.

D) Dibujando musgos con la ayuda de una lupa para aprender a utilizar la lupa correctamente. Fotos: J. Malebrán

Las metáforas creadas por investigadores y estudiantes de postgrado que utilizan la FILAC como método de investigación, son utilizadas por ellos y el resto del equipo del Parque en las actividades de difusión y educación ambiental. En el curso TDP, la práctica de componer metáforas es fundamental para el proceso de aprendizaje que promueve la abstracción y el pensamiento analógico para poder comunicar lo que han aprendido a sus compañeros y a la sociedad. En términos de uno de los profesores del TDP, Cristian Formoso, escritor: Es decir una cosa por otra... Es una representación de algo por otro algo... Es describir una cosa con otras palabras o con la imagen de otra cosa. Formoso señala que el proceso de composición de metáforas consta de tres pasos secuenciales.

Comparación: Buscar similitudes entre dos elementos u objetos distintos o que no tienen ninguna relación concreta.

Imagen: Se elimina la comparación para afirmar que el segundo elemento es equivalente al primero.

Metáfora: Se elimina el primer elemento, pero se encuentra implícito en la oración. La frase genera una imagen mental de lo que se procura evocar. 


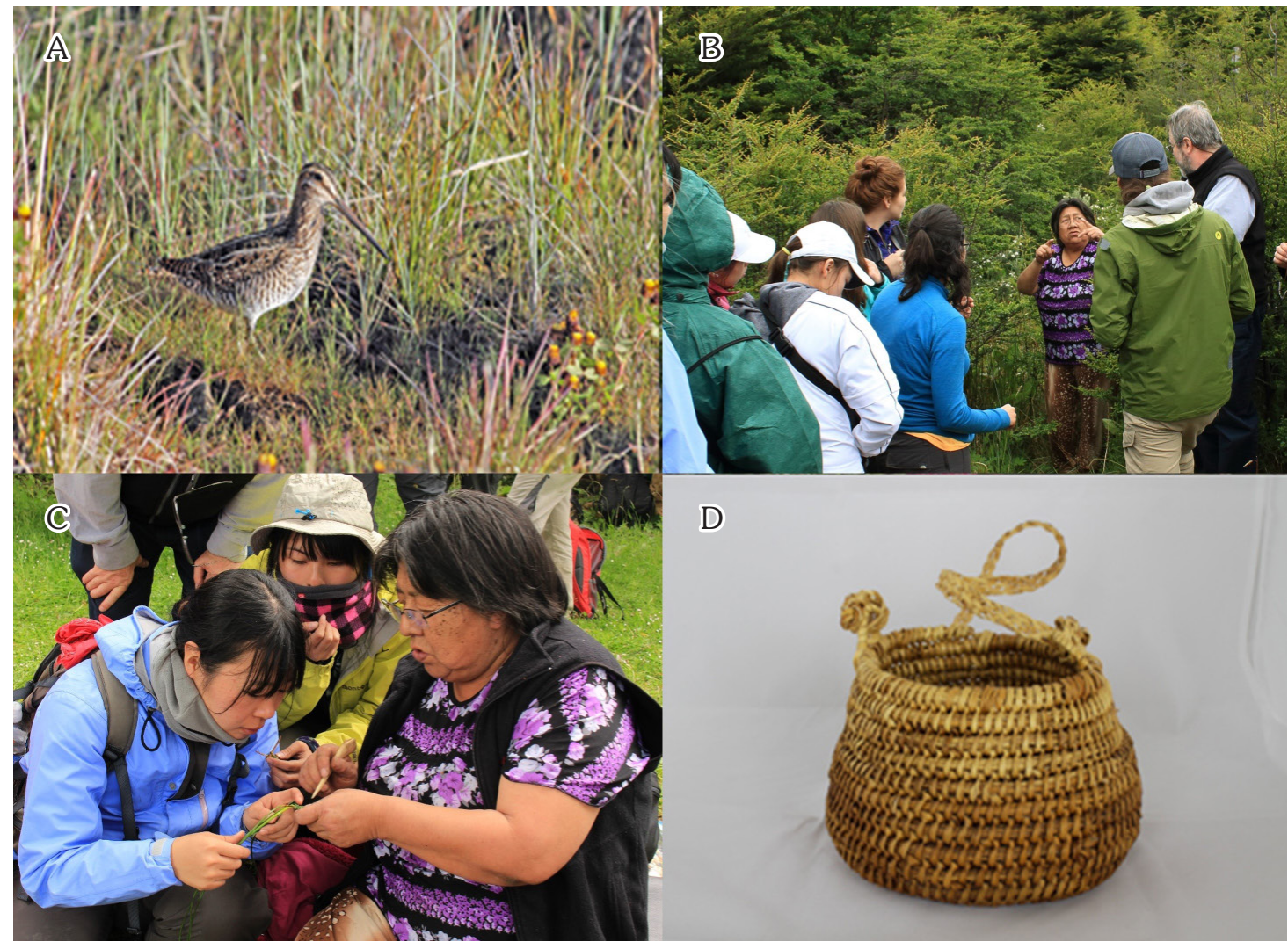

Fig. 5. Estudiantes durante una actividad en terreno con Julia González, artesana yagán, en el Parque Omora. (A) El hábitat de humedal provee las fibras vegetales necesarias para el hábito del tejido de canastos y también los recursos de alimentación y hábitos de reproducción de aves como la becasina (Gallinago paraguaiae magellanica). (B-C) Los artesanos de la comunidad yagán ofrecen a los estudiantes experiencias compartidas y les enseñan el proceso de recolección y cocción de las fibras vegetales, y el tejido de canastos. (D) Además, les muestran sus artesanías, tales como los cestos de junco, utilizados tradicionalmente para la recolección de frutos. Fotos: (A) Jordi Plana, (B) Javiera Malebrán, (C) Bruno Becker y (D) Cristian Valle.

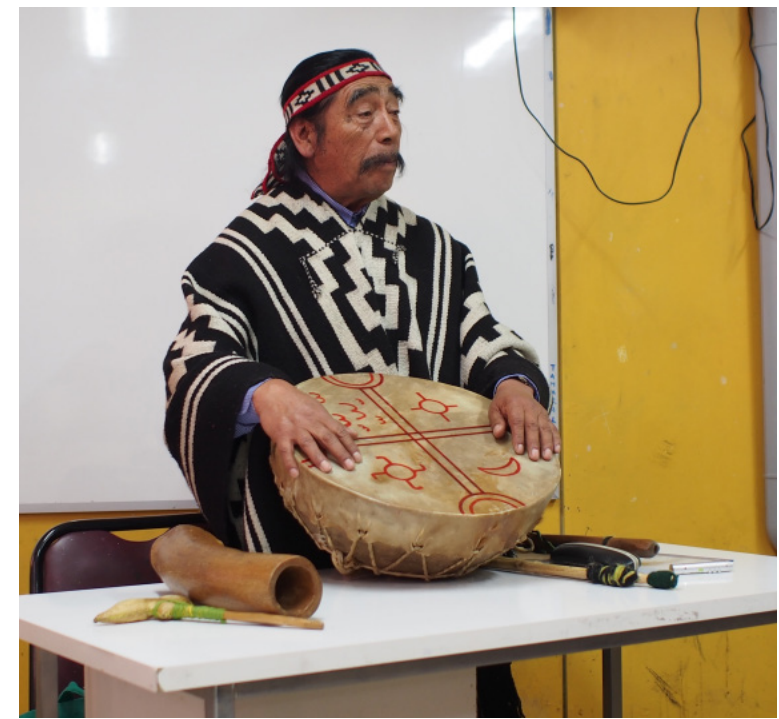

Paso 3:

Diseño de experiencias de campo guiadas

Las experiencias y aprendizajes de los pasos 1 y 2 se utilizan para el diseño de actividades de terreno guiadas. Para ello, los alumnos trabajan en grupos desarrollando y creando actividades de campo guiadas orientadas con un sentido ecológico y ético.

Estas actividades deben promover encuentros directos, cara-a-cara, donde las personas que visitan el Parque puedan interactuar con todos los

Fig. 6. El poeta Lorenzo Aillapan muestra a los alumnos algunos de los instrumentos tradicionales de la cultura mapuche a través de sus interpretaciones de poesía, música y cantos de las aves de los bosques y las costas (Foto: Megan Fitch). 
seres y elementos que componen un ecosistema y aprender de ellos. Esta interacción busca estimular la percepción y valoración de la diversidad biológica y cultural en un lugar y momento dados. Como resultado, se generan lazos entre los visitantes y los seres y elementos observados.

Paso 4:

Diseño e implementación de señalética en senderos interpretativos

Pedagógicamente, este paso tiene un doble objetivo. Primero, integrar creativamente los conceptos, reflexiones y valores comprendidos en el trabajo realizado en los tres pasos anteriores. Segundo, fomentar un sentido de servicio y responsabilidad con la conservación biocultural insitu. Una práctica que integra estos dos objetivos es el diseño y confección de señaléticas que son instalados en senderos interpretativos. Estas instalaciones son funcionales a los objetivos de la filosofía ambiental de campo, que considera la implementación de senderos y estaciones interpretativos que orienten encuentros cara-a-cara de los visitantes con aves, musgos, invertebrados y otros componentes de la diversidad biológica y cultural. En estos espacios, los visitantes aprecian también los valores biocultural, estético, intrínseco e instrumental de esta biodiversidad, como también la necesidad de la protección de los hábitats y las interacciones ecológicas dentro de las comunidades. En suma, los estudiantes habilitan espacios que permiten a otros visitantes, experimentar, observar y disfrutar in-situ de estas interacciones y valores $y$ coexistir por un momento, inmersos en esta diversidad biocultural.

Para cumplir con los objetivos pedagógicos de este paso (integración de lo aprendido y fomento de un sentido de servicio y responsabilidad), los estudiantes se dividen en grupos y discuten cómo traducir a una imagen los conceptos contenidos en las metáforas (Paso 2), y dibujan sus bosquejos en papel y desarrollan actividades de terreno con sentido filosófico y ético (Paso 3). A partir de este trabajo grupal surgen diseños para la confección de uno o más letreros interpretativos. Los dibujos se traspasan a tablillas de madera donde se demarcan con la técnica de pirograbado. Las tablillas son selladas con barniz vitrificante y son instaladas en los senderos interpretativos del Parque Omora $\mathrm{u}$ otras áreas de la Isla Navarino.

\section{RESULTADOS Y DISCUSIÓN}

\section{Composición de los \\ participantes en el curso FILAC}

Para lograr un enfoque socio-ambiental más amplio, que integre las humanidades, las artes y la ética ambiental en los programas de investigación y educación en las redes LTSER-Chile e ILTER, el curso TDP plantea la necesidad de la participación de distintos grupos de personas que provengan de diferentes edades, disciplinas y regiones geográficas. En las últimas cuatro versiones del TDP (20152018), los participantes internos, es decir, profesores, alumnos y profesionales del Parque Omora, que interactúan estrechamente durante todo el desarrollo del curso, han totalizado 200 personas. Entre ellas se incluyeron 111 estudiantes (92 de pregrado y 19 de postgrado); 57 profesores, 8 ayudantes de diversas áreas del conocimiento y 24 asistentes que han incluido técnicos, postdoctorantes, alumnos en práctica y profesionales del Parque Omora (Tabla 1).

\section{Experiencias}

interdisciplinarias e interculturales

Con el fin de alcanzar una experiencia transdisciplinaria, cada año los participantes de TDP han interactuado con: i) miembros y estudiantes de la comunidad local, ii) investigadores que visitan el Parque Omora por otras razones, y iii) autoridades locales, regionales, nacionales $y / 0$ internacionales (Tabla 2).

Tabla 1. Participantes en los cursos de Filosofía Ambiental de Campo entre los años 2015 y 2018.

\begin{tabular}{lccccc}
\hline Participantes & 2015 & 2016 & 2017 & 2018 & Total \\
\hline Estudiantes & 30 & 25 & 29 & 27 & 111 \\
Académicos & 17 & 16 & 15 & 17 & 65 \\
Asistentes & 7 & 6 & 5 & 6 & 24 \\
\hline Total & 54 & 47 & 50 & 49 & 200 \\
\hline
\end{tabular}


Tabla 2. Personas de la comunidad con quienes se interactúa durante los cursos de Filosofía Ambiental de Campo entre los años 2014 y 2017.

\begin{tabular}{cccccc}
\hline Grupos de personas & 2015 & 2016 & 2017 & 2018 & Total \\
\hline Academia & 135 & 35 & 78 & 15 & 248 \\
Autoridades & 15 & 5 & 6 & 5 & 26 \\
Comunidad local & 50 & 8 & & 30 & 58 \\
\hline Total & 200 & 48 & 84 & 50 & 332 \\
\hline
\end{tabular}

Tabla 3. Detalle de personas con quienes los estudiantes han tenido encuentros durante las últimas cuatro versiones del curso TDP.

\begin{tabular}{|c|c|c|c|}
\hline Año & Academia & Autoridades & Comunidad local \\
\hline 2015 & $\begin{array}{l}\text { International Association of } \\
\text { Bryologists Conference }\end{array}$ & $\begin{array}{l}\text { Presidente de Chile, } \\
5 \text { Ministros, Parlamentarios } \\
\text { regionales y nacionales, } \\
\text { Gobernador, Alcalde }\end{array}$ & $\begin{array}{l}\text { Grupo Asparnij, Artesanos y } \\
\text { otros miembros de la Comunidad } \\
\text { Indígena Yagán de Bahía } \\
\text { Mejillones }\end{array}$ \\
\hline 2016 & $\begin{array}{l}\text { VIII Southern Connection } \\
\text { Conference }\end{array}$ & Gobernador, Alcalde & $\begin{array}{l}\text { Artesanos y otros miembros de } \\
\text { la Comunidad Indígena Yagán de } \\
\text { Bahía Mejillones }\end{array}$ \\
\hline 2017 & $\begin{array}{l}\text { II Congreso del Futuro (Premios } \\
\text { Nobel) }\end{array}$ & Senador, Almirante & $\begin{array}{l}\text { Artesanos y otros miembros de } \\
\text { la Comunidad Indígena Yagán de } \\
\text { Bahía Mejillones }\end{array}$ \\
\hline 2018 & $\begin{array}{l}\text { Académicos y autoridades de } \\
\text { las universidades de Magallanes, } \\
\text { Católica de Chile y de North } \\
\text { Texas. }\end{array}$ & Gobernador, Alcalde & $\begin{array}{l}\text { Escolares del Taller Omora del } \\
\text { Medioambiente en el Liceo de } \\
\text { Puerto Williams }\end{array}$ \\
\hline
\end{tabular}

La Tabla 3 muestra la proveniencia específica de las personas con quienes los estudiantes del curso TDP tuvieron encuentros durante el período analizado. Los miembros de la comunidad local incluyeron miembros de la Comunidad Indígena Yagán de Bahía Mejillones y profesores y estudiantes del Liceo Donald McIntyre (único establecimiento educacional escolar de Puerto Williams). También se han sostenido regularmente encuentros con científicos, que incluyen premios Nobel, como también investigadores residentes que conducen de proyectos de investigación en el Parque Omora. Las autoridades han incluido presidentes de la República, ministros de Estado, parlamentarios, gobernadores, alcaldes, autoridades navales, entre otras.

\section{Encuentros inter-culturales}

Los participantes de TDP han provenido de distintos continentes: América (Norte y Sur), Asia y Europa. Respecto a la distribución geográfica, entre los estudiantes de pregrado hay una marcada prevalencia de estudiantes estadounidenses con un $86,9 \%$ del total, y académicos chilenos con un $56,9 \%$. La proporción en la procedencia de los alumnos de posgrado más balanceada, con solo 42,1\% de estudiantes estadounidenses (Fig. 7).

Aunque el curso se dicta principalmente en inglés, siendo éste un requisito para la postulación; la diversidad de países de origen de los participantes implica que en muchos casos el idioma nativo no es el inglés. Esta característica enriquece la experiencia intercultural de quienes se esfuerzan por comprender mejor a aquellos que hablan otro idioma, aprendiendo palabras o conceptos básicos (generalmente en español), o esforzándose por explicar mejor y en términos más simples lo que intentan decir. Sin embargo, los estudiantes de habla no inglesa y que no dominan completamente este idioma se encuentran en desventaja al momento de 
Total de participantes por origen geográfico

50

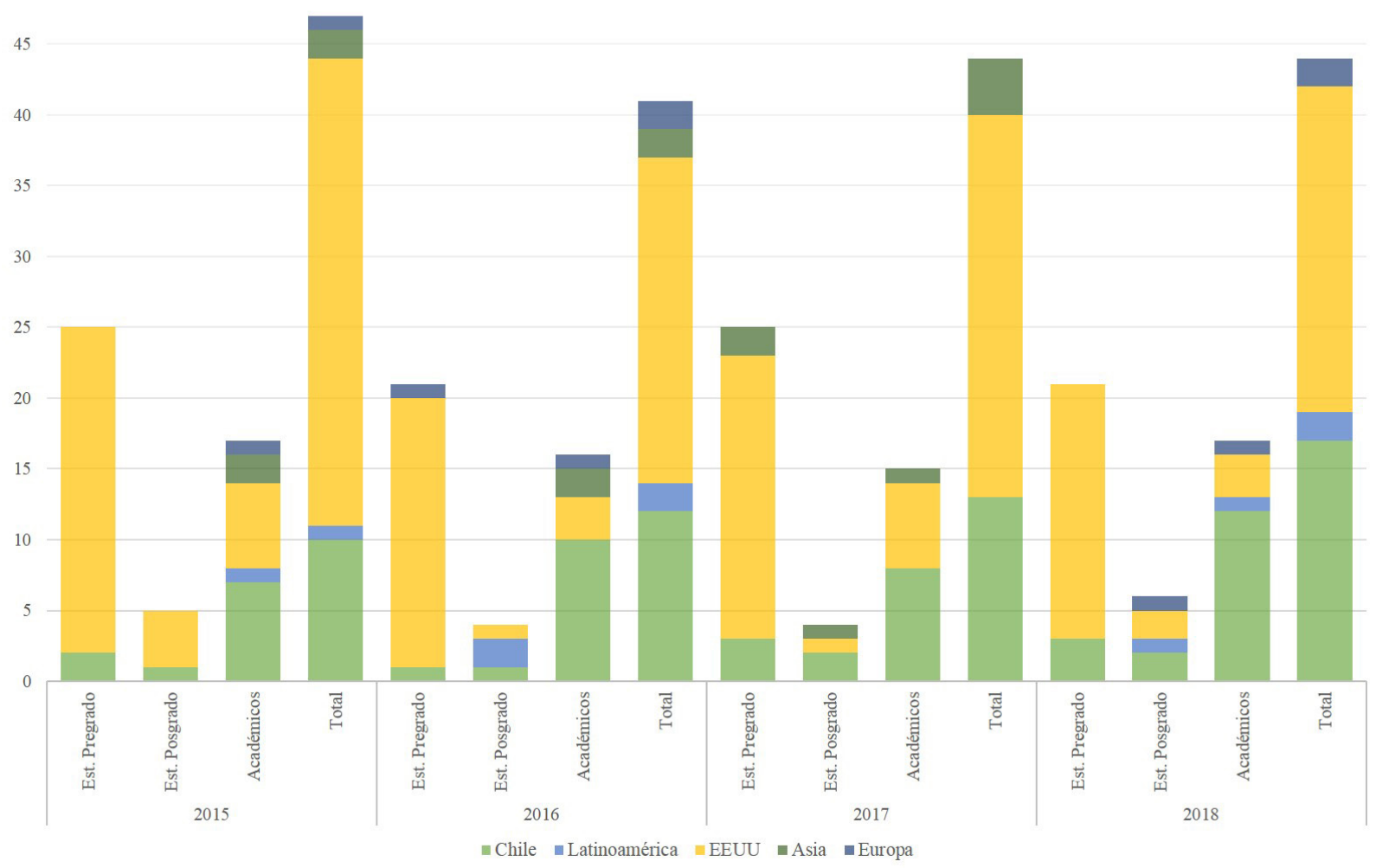

Fig. 7. Total de participantes de los cuatro cursos evaluados en este trabajo por origen geográfico, según año y según nivel académico.

aprehender los contenidos expuestos. En ocasiones esto ha generado barreras de comunicación entre los participantes que se refleja en una menor interacción entre ellos.

Respecto a la procedencia disciplinaria, la mayoría de los alumnos de pre y posgrado tienen su foco de estudios en las ciencias naturales (68,5\%). Los estudiantes de filosofía y otras humanidades (ie. historia, literatura, comunicación) corresponden al $12,6 \%$. Aunque el número de estudiantes de artes es bajo en comparación al total $(3,6 \%)$, existe un gran número de artistas en el cuerpo académico, incluyendo artistas plásticos, músicos y escritores, con un $20,0 \%$ del total. Finalmente, existe un número considerable $(9,9 \%)$ de estudiantes de las ciencias sociales (eg. antropología, sociología, geografía) y otras disciplinas como ingeniería, informática y derecho $(5,4 \%)$.

Losacadémicosyestudiantes han pertenecido a cuatro ámbitos disciplinarios amplios: i) ciencias naturales y ambientales, ii) ciencias sociales, iii) artes y iv) filosofía y otras humanidades (Fig. 8). Estas distintas disciplinas, además de los contextos geográficos y culturales (idiosincrasia e idioma) del cual provienen los participantes, aportan al grupo una visión particular y distintas formas de abordar preguntas y problemas ecológicos y filosóficos.

Desarrollo del ciclo de cuatro pasos de la FILAC

Cada uno de los pasos del ciclo de la FILAC entrega nuevas herramientas y perspectivas. En el Paso 1, los participantes conocen $y$ aprenden a valorar los saberes ancestrales de los pueblos originarios como también de tradición de pensamiento de la civilización occidental, y descubren nuevas escalas espaciales y temporales 
TOTAL DE PARTICIPANTES POR DISCIPLINA

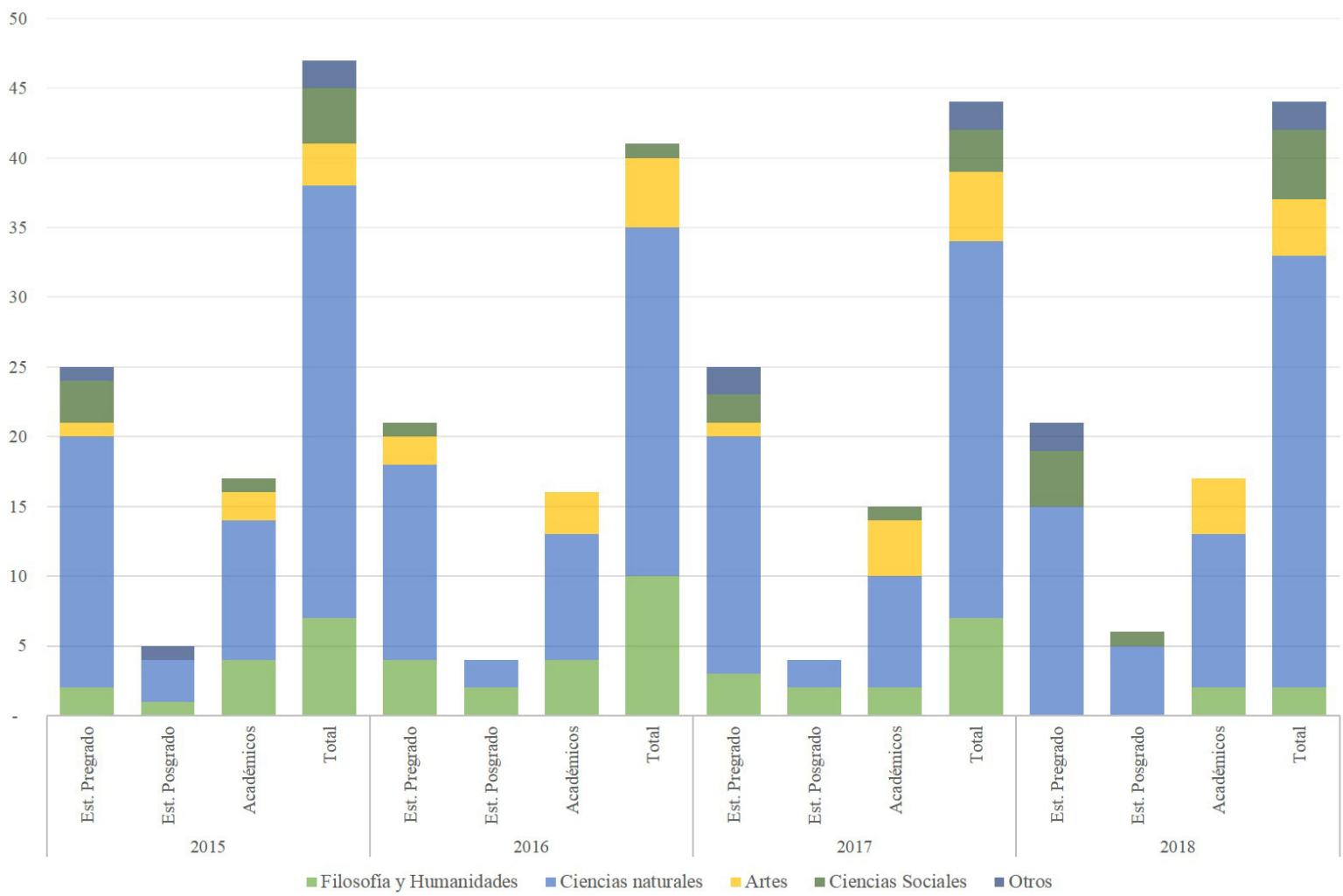

Fig. 8. Total de participantes de los cuatro cursos evaluados en este trabajo por disciplina o ámbito académico, según año, y según nivel académico (estudiantes de pre y posgrado y profesores y ayudantes).

en los sistemas ecológicos. La diversidad de contextos de los cuales los participantes provienen, sumado a estas experiencias eco-hermenéuticas en terreno, propicia un ambiente donde desarrollan un pensamiento crítico que fomenta el cuestionamiento de paradigmas prevalecientes pero problemáticos en el modo de relacionarse con la naturaleza.

Una actividad particularmente significativa para al alcanzar una comprensión intercultural es la experiencia en terreno con la artesana yagán Julia González y sus pequeñas nietas, que siempre la acompañan. En esta experiencia los participantes son guiados por Julia en el tejido de una cesta que integra la colecta de las fibras vegetales en un humedal, la cocción del material en una fogata y la técnica del tejido. En esta instancia, altamente valorada por los alumnos, la comunicación trasciende a las palabras. A través de esta práctica, los participantes logran comprender y valorar un conocimiento ecológico ancestral. Bajo el marco conceptual de la ética biocultural, este tipo de experiencia de aprendizaje in situ contribuye a la comprensión de la necesidad de proteger los hábitats (como el humedal), las comunidades de co-habitantes (humanos, otros animales y plantas), que hacen posibles hábitos tradicionales (como la práctica del tejido de cestas). Los estudiantes se benefician de la riqueza de una vivencia biocultural integral, mientras que los miembros de la comunidad yagán reciben mayor apreciación de su identidad biocultural, a la vez que obtienen reconocimiento cultural y económico.

En el Paso 2, los participantes desarrollan el pensamiento analógico para crear metáforas y narrativas simples que explican procesos complejos. Para ello los participantes deben comprender muy bien lo que procuran explicar, de forma que las metáforas sean simples a la vez que efectivas. Este proceso es el resultado de un trabajo de re-conexión tanto con los diferentes elementos de la naturaleza 
observados como con las diferentes perspectivas de los estudiantes. Se refieren, en su mayoría, a las experiencias recientes y evocan en los demás participantes momentos compartidos en los días anteriores. Estas metáforas aluden a experiencias vividas por los alumnos durante el curso. Bajo el marco conceptual de la ética biocultural, posibilitan un puente entre el dominio biofísico y el lingüístico, que conduce a una compresion biocultural. Algunas metáforas compuestas en los cursos TDP incluyen las siguientes.

- The cleaning crew of the Robalo river / "El equipo de limpieza del río Robalo". Alude a los distintos grupos de macroinvertebrados dulceacuícolas del río Róbalo que, a través de sus hábitos alimenticios, limpian el agua de la hojarasca de los árboles y otros restos vegetales que caen al agua.

- The steps of the forest / "Los escalones del bosque". Hace referencia a las raíces de los árboles en las laderas que, al erosionarse la tierra, forman escaleras que sirven de apoyo para subir.

- The veins of the earth / "Las venas de la tierra". Analogía entre el sistema circulatorio de los animales y los ríos en los ecosistemas. El agua de los ríos, al igual que la sangre en las venas, mueve nutrientes, desechos y está lleno de vida.

- The faces of the river / "Los rostros del río". Se refiere a las caras o rostros de los macroinvertebrados dulceacuícolas, que son posibles de ver en la actividad "Sumergidos con Lupa"

- The sponges of the earth / "Las esponjas de la tierra". Hace referencia a los musgos y turberas, y su gran capacidad de absorción de agua.

- A bridge between the earth and the sky / "Un puente entre el cielo y la tierra". Ejemplifica la conexión que generan los árboles entre el suelo (raíces) y el aire (ramas y hojas) y como todo el flujo de energía y nutrientes genera un espiral de energía. Por ejemplo, los nutrientes de las hojas, llegan a las raíces en el otoño y vuelven a ser hojas en la primavera

- The voices of the forest / "Las voces del bosque". Evoca los sonidos del bosque, desde el flujo del agua hasta el canto de las aves o el repicar de un pájaro carpintero en un árbol.

La composición de narrativas y metáforas integra los "lentes conceptuales" provistos por la filosofía con los "lentes personales" de cada uno de los participantes. Como resultado de esta integración, han surgido novedosas formas de ver y comprender complejas interacciones ecosistémicas, o incluso ecosistemas en general. Éstos pueden ser definidos en nuevos términos, que complementan las definiciones existentes bajo las miradas de la ciencia. Un ejemplo de esto son las distintas respuestas de los alumnos del TDP 2015 ante la pregunta ¿cómo describirían ustedes la cuenca del río Róbalo?

Mientras que los alumnos provenientes de un contexto académico científico coincidían en una visión ecosistémica y biofísica de la integración de los cerros y bosques en las dinámicas de los ríos, esteros y lagos (ver Vannote et al. 1980), un estudiante de economía lo describió como un sistema económico de entradas y salida de capital, efectos de tasas de interés, devaluación de moneda, ahorro, etc. Por otro lado, una estudiante de artes escénicas comparó la trayectoria del río con el hilo argumental de la obra de William Shakespeare, "Hamlet". El nacimiento del río es el primer acto, donde se plantean los antecedentes de la historia y se presentan los personajes principales. Los tres lagos que existen en el valle son los tres actos siguientes, donde se desarrolla la mayor parte de la historia y donde cada pequeño estero tributario del río es un nuevo personaje de la obra. El quinto acto corresponde al encuentro del río con el mar en el canal Beagle, y es la conclusión de la historia.

Un ejemplo de las actividades guiadas generadas en los cursos es el Juego de las Microalgas y los Hongos, ideado por uno de los grupos de estudiantes del TDP 2018. Basándose en los conocimientos adquiridos sobre la estructura y formación de los líquenes, la actividad consiste en que una sección de los participantes (los hongos) deben formar un círculo, mientras que una parte más pequeña (las microalgas) debe estar en el interior, con los ojos cubiertos. Al igual como las microalgas buscan a su contraparte fúngica en la naturaleza, los participantes dentro del círculo deben encontrar a sus compañeros que los rodean; para esto las microalgas llaman a viva voz "hongo" y 
los hongos responden "microalga", para ayudarles a orientarse. Una vez que la microalga encuentra al hongo, este la abraza, simulando la forma en que el haustorio del hongo atrapa la microalga para formar un liquen. A través de esta dinámica no solo se explica una interacción ecológica, sino también se demuestra la importancia de la colaboración y el trabajo en equipo.

El último paso ha significado trabajo en distintos niveles que logran el doble objetivo pedagógico deseado. La confección de señaléticas interpretativas reúne en una imagen y/o frase los conceptos, valores y reflexiones provenientes del trabajo realizado durante el curso, de forma individual y grupal. También genera un sentimiento de pertenencia y responsabilidad con los lugares donde estas señaléticas son instaladas. Los letreros se diseñan, en general, para un punto en específico de un sendero. Esto significa que quienes han participado en la confección de los letreros forman un lazo con sus compañeros de grupo y con el lugar donde se instala.

La diversidad es un aspecto central tratado en los contenidos del curso TDP, lo que también se refleja en la diversidad de sus participantes. La gran diversidad en el contexto y antecedentes personales de cada participante, sumado al rico y desafiante contexto biofísico y cultural de los ecosistemas subantárticos, generan un ambiente académico formal e informal, donde todos los participantes interactúan entre ellos y viven encuentros directos con la belleza y complejidad del ecosistema en que se encuentran inmersos. Se ven enfrentados de forma concreta a algunas de los desafíos que presenta el trabajo de conservación biocultural, investigación interdisciplinaria e incluso la vida cotidiana en un lugar tan aislado.

Estas experiencias en terreno exponen a los alumnos a tener encuentros con seres humanos y otros-que-humanos, en medio de un ambiente natural prístino (Fig. 3); trascendiendo a aquellas experiencias que los estudiantes en general viven en el escenario educacional clásico, es decir, la sala de clases, donde ocurre la mayor parte de la educación, en todos los niveles. En el contexto del TDP, la sala de clases son los hábitats donde ocurren las interacciones de los participantes con los co-habitantes humanos y otros-que-humanos. Es la orilla del mar, un lago o un río, es el medio de un bosque, una playa rocosa del canal Beagle o la belleza del ecosistema altoandino. El techo es el cielo azul, las nubes oscuras que presagian un aguacero o las ramas de los árboles. La luz son los rayos del sol o las llamas de una fogata (Fig. 3). En estos hábitats los participantes del curso entablan conversaciones horizontales con sus compañeros y profesores, y desarrollan sus propios análisis, cuestionando ideas preconcebidas y generando nuevas ideas que integran los múltiples puntos de vista (o "lentes conceptuales" como les llamamos nosotros), y que cada uno selecciona, evalúa, adapta y hace propios o no.

Al conversar con estudiantes que han pasado por esta experiencia, en la mayoría de los casos, hemos escuchado comentarios que la describen como algo que cambió sus vidas y continúan recordando las experiencias vividas durante el curso durante los años siguientes, volviendo a analizar situaciones o conversaciones. Otro aspecto importante es que los estudiantes tienen la posibilidad de analizar el mundo a su alrededor de forma mucho más crítica, descubrir detalles de sus entornos que antes habrían pasado por alto, aumentar su capacidad de tolerancia y empatía y convertirse en promotores de cambio en sus familias, amigos y colegas.

\section{Aplicación de la FILAC en sitios} de la red LTSER-CHILE e ILTER

La experiencia del TDP ha entregado a los alumnos las herramientas necesarias para guiar a grupos de visitantes por los senderos del Parque Omora. Hasta la fecha varios exalumnos de este curso se han desempeñado como guías especializados en el Parque Omora guiando a una variedad de visitantes, grupos de turistas, miembros de la comunidad local y otros a través de los senderos y estaciones de observación del parque. También han colaborado con los profesionales del parque en los programas de monitoreo a largo plazo y en otros proyectos de investigación. Durante la realización de los cursos, han participado como guías de estaciones interpretativas en el Parque Omora 
en el Congreso de la Asociación Internacional de Briología (2015), el congreso Southern Connection (2016), el Congreso del Futuro (2017) y la visita de una comitiva de autoridades académicas de la Universidad de Magallanes y la Pontificia Universidad Católica de Chile y la University of North Texas de EE.UU (2018). En las cuatro versiones del TDP analizadas, los alumnos del curso en calidad de guías del parque mostraron a los visitantes la diversidad de ecosistemas que se pueden encontrar a lo largo de los senderos, como su conjunto de cohabitantes. Los estudiantes compartieron con los visitantes sus propias experiencias y aprendizajes, y los visitantes, a su vez, pudieron apreciar empíricamente la importancia del programa de educación del Parque Omora y el impacto que cursos como el TDP pueden tener en estudiantes de diversos lugares del mundo.

La FILAC genera puentes entre la sociedad y la naturaleza combinando actividades de investigación, creación poética y conservación. Los cursos realizados en el Parque Omora han estado dirigidos especialmente a estudiantes que provienen de contextos urbanos donde, según Maturana (1997), ocurre una fuerte desconexión con nuestro fundamento animal y vegetal. Este fundamento es tan relevante desde la comprensión biológica y ética, que los seres vivos (humanos y otros-que-humanos) y componentes de los ecosistemas son considerados como cohabitantes. Esta comprensión se sustenta en el marco teórico de la ética biocultural que interrelaciona los hábitos de vida con hábitats específicos y con las comunidades que co-habitan en ellos (Rozzi et al. 2008).

Una gran ventaja de los sitios de estudio a largo plazo es la presencia permanente de investigadores y técnicos trabajando in situ, interactuando con la comunidad $e$ instituciones locales y regionales. Esto implica la integración del grupo de investigadores y estudiantes con la comunidad local, lo cual fomenta mejores y nuevas formas de trabajo en conjunto. Los sitios ILTER poseen infraestructura que puede ser utilizada para actividades de difusión y educación ambiental. En general, son parte de redes de trabajo que reúnen a investigadores y estudiantes de diversos lugares del mundo, que contribuyen a aportar al conocimiento e integración de perspectivas a escala local y global; una integración que es esencial para afrontar el rápido cambio socio-ambiental global.

El ciclo de la FILAC puede ser fácilmente adaptada a las realidades locales. Es un ciclo donde cada paso está conectado con los otros, de forma que se retroalimentan constantemente. A partir del trabajo en uno de los pasos, pueden surgir nuevas preguntas o nuevas ideas que llevan de regreso al Paso 1. Así, la aplicación de la FILAC estimula la generación de nuevos conocimientos científicos y filosóficos a través de la investigación interdisciplinaria. Además, la inclusión de los distintos grupos sociales asociados a la diversidad biocultural local promueve la generación de conocimientos que son mucho más amplios y profundos. De esta manera se pueden comprender mejor las problemáticas socio-ambientales de las comunidades locales y potenciar programas de educación ambiental y conservación biológica y cultural de forma integrada, y fomentan la creación y mantenimiento de áreas protegidas.

\section{AGRADECIMIENTOS}

Los autores agradecen a todos los profesores y estudiantes del Liceo Donald MacIntyre de Puerto Williams que han participado en los cursos, a los miembros de la Comunidad Indígena Yagán que han participado en diversas actividades en los congresos, talleres y otras actividades asociadas a los cursos TDP, a las autoridades civiles y navales, al Ferry Yahgan, y al equipo de trabajo del Parque Etnobotánico Omora. Agradecemos también las revisiones y comentarios de Francisca Massardo y MaríaTeresa La Valle, el apoyo institucional de la Universidad de Magallanes, la Universidad de Chile, la University of North Texas y el Instituto de Ecología y Biodiversidad de Chile a través de los proyectos CONICYT PFB-23 y Apoyo a Centros Científicos y Tecnológicos de Excelencia con Financiamiento Basal CONICYT AFB170008. JM también agradece al profesor Ramiro Bustamante de la Universidad de Chile por el constante apoyo a este trabajo, y a Natalia Malebrán, por la confección del mapa de la Fig. 1. 


\section{BIBLIOGRAFÍA}

Arango X, Rozzi, R., Massardo, F., Anderson, C. B., \& Ibarra, J. T. (2007). Discovery and implementation of Magellanic woodpecker (Campephilus magellanicus) as an emblematic species: A biocultural approach for conservation in Cape Horn Biosphere Reserve. Magallania, 35, 71-88.

Contador, T., Rosenfeld, S., Ojeda, J., \& Kennedy, J., (2015). Historia natural de los invertebrados acuáticos del Cabo de Hornos, Fundación Omora. Punta Arenas: Ediciones Universidad de Magallanes.

Goffinet, B. (2012). Miniature forests of Cape Horn: ecotourism with a hand lens. Texas: University of North Texas Press.

Goffinet, B., Rozzi, R., Lewis, L., Buck, W., Massardo, F., (2012). Miniature Forests of Cape Horn: Ecotourism with a Hand Lens. University of North Texas Press.

Leopold, A. (1949). A Sand County Almanac. New York: Oxford University Press.

Leopold, C. (2004). Living with the Land Ethic. BioScience, 54, 149-154.

Maass, M., Balvanera, P., Bourgeron, P., Equihua, M., Baudry, J., Dick, J., Orenstein, D. E.,... \& Vădineanu, A. (2016). Changes in biodiversity and trade-offs among ecosystem services, stakeholders, and components of well-being: the contribution of the International Long-Term Ecological Research network (ILTER) to Programme on Ecosystem Change and Society (PECS). Ecology and Society 21(3). https://www. ecologyandsociety.org/vol21/iss3/art31/

Maass, M., \& Equihua, M. (2014). The International Long Term Ecological Research (ILTER) network after 20 years since its creation: advances and challenges. Bosque, 35(3), 415-419.

Massardo, F., \& Rozzi, R. (2006). The World's Southernmost Ethnoecology: Yahgan Craftsmanship and Traditional Ecological Knowledge. Gobierno Regional de Magallanes y Antártica ChilenaUniversidad de Magallanes.

Maturana, H. (1997). Prólogo. En, R. Rozzi, P. Feinsinger, \& R. Riveros (Eds.). La enseñanza de la Ecología en el Entorno Cotidiano (pp. 3-7). Santiago de Chile: Ediciones Ministerio de Educación de Chile.

Oelschlaeger, M., \& Rozzi, R. (1998). El nudo gordiano interdisciplinario: un desafío para la sustentabilidad. Ambiente y Desarrollo, 14, 71-81.

Poole, A. K. (2015). Urban Sustainability and the
Extinction of experience: Acknowledging Drivers of Biocultural Loss for Socio-Ecological WellBeing. Ph.D. Dissertation in Philosophy, University of North Texas, Denton, Texas.

Rozzi, R. (1999). The reciprocal links between evolutionaryecological sciences and environmental ethics. BioScience, 49(11), 911-921

Rozzi, R. (2013). Biocultural ethics: from biocultural homogenization towards biocultural conservation. Linking Ecology and Ethics for a Changing World (pp. 9-32). Netherlands: Springer.

Rozzi, R. (2015). Ética biocultural: una ampliación del ámbito socioecológico para transitar desde la homogeneización biocultural hacia la conservación biocultural. En B. Bustos, M. Prieto \& J. Barton (Eds.), Ecología Política en Chile: Naturaleza, Propiedad, Conocimiento y Poder (pp. 89-117). Santiago de Chile: Ediciones Universidad de Chile.

Rozzi, R. (2018). Transformaciones del pensamiento de Darwin en cabo de hornos: un legado para la ciencia y la ética ambiental. Magallania, 46(1), 277-287.

Rozzi, R., \& Jiménez, J. E. (2014). Ornitología Subantártica de Magallanes: Primera Década de Estudios de Aves en el Parque Etnobotánico Omora, Reserva de Biosfera Cabo de Hornos. Punta Arenas-Denton: Universidad de Magallanes, Chile-University of North Texas Press.

Rozzi, R., Arango, X., Massardo, F., Anderson, C., Heidinger, K., \& Moses, K. (2008). Filosofía ambiental de campo y conservación biocultural: el programa educativo del Parque Etnobotánico Omora. Environmental Ethics, 30(Suplemento), 115-128.

Rozzi, R., Anderson, C. B., Pizarro, J. C., Massardo, F., Medina, Y., Mansilla, A. O., \& Moses, K. (2010). Filosofía ambiental de campo y conservación biocultural en el Parque Etnobotánico Omora: Aproximaciones metodológicas para ampliar los modos de integrar el componente social ("S") en Sitios de Estudios Socio-Ecológicos a Largo Plazo (SESELP). Revista Chilena de Historia Natural, 83(1), 27-68.

Rozzi, R., Armesto, J. J., Gutiérrez, J. R., Massardo, F., Likens, G. E., Anderson, C. B., \& Kennedy, J. H. (2012a). Integrating ecology and environmental ethics: earth stewardship in the southern end of the Americas. BioScience, 62(3), 226-236.

Rozzi, R., Lewis, L., Massardo, F., Medina, Y., Moses, K., Méndez, M., \& Goffinet, B. (2012b). Ecotourism With a Hand-lens in Omora Park. Punta Arenas- 
Denton: Ediciones Universidad de Magallanes-UNT Press.

Rozzi, R., Massardo, F., Contador, T., Crego, R. D., Méndez, M., Cavieres, L. A., \& Jiménez, J. E. (2014). Filosofía ambiental de campo: ecología y ética en las redes LTER-Chile e ILTER. Bosque, 35(3), 439-447.

Schuttler, E., Klenke, R. McGehee, S. Rozzi, R., \& Jax, K. (2009). Vulnerability of ground-nesting waterbirds to predation by invasive American mink in the Cape Horn Biosphere Reserve, Chile. Biological Conservation, 142, 1450-1460.

UN (2010). World Urbanization Prospects: The 2007
Revision Population Database. United Nations, Population Division: New York (http://esa.un.org/ unup).

Vannote, R. L., Minshall, G. W., Cummins, K. W., Sedell, J. R., \& Cushing, C. E. (1980). The river continuum concept. Canadian Journal of Fisheries and Aquatic Sciences, 37(1), 130-137.

Villagrán, C., Segovia, R., \& Castillo, L. (2014). Principios de la investigación en ciencias naturales históricas: ¿Por qué en biología es necesaria la Historia Natural de los organismos? Gayana Botánica, 71(2), 259266. 
